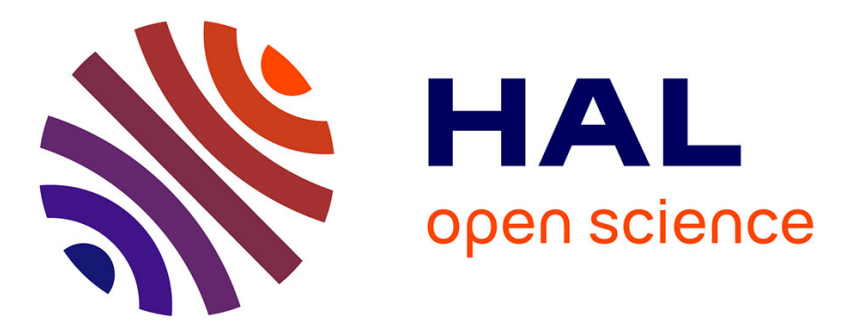

\title{
Partial wing transparency works better when disrupting wing edges: evidence from a field experiment
}

Mónica Arias, Lucie Leroy, Clément Madec, Louane Matos, Cynthia Tedore, Marianne Elias, Doris Gomez

\section{- To cite this version:}

Mónica Arias, Lucie Leroy, Clément Madec, Louane Matos, Cynthia Tedore, et al.. Partial wing transparency works better when disrupting wing edges: evidence from a field experiment. Journal of Evolutionary Biology, 2021, 10.1111/jeb.13943 . hal-03373157

\section{HAL Id: hal-03373157 \\ https://hal.science/hal-03373157}

Submitted on 20 Oct 2021

HAL is a multi-disciplinary open access archive for the deposit and dissemination of scientific research documents, whether they are published or not. The documents may come from teaching and research institutions in France or abroad, or from public or private research centers.
L'archive ouverte pluridisciplinaire HAL, est destinée au dépôt et à la diffusion de documents scientifiques de niveau recherche, publiés ou non, émanant des établissements d'enseignement et de recherche français ou étrangers, des laboratoires publics ou privés. 
Title: Partial wing transparency works better when disrupting wing edges: evidence from a field experiment

Running title: transparency works better when disruptive

Authors: Mónica Arias ${ }^{1,2}$ (https://orcid.org/0000-0003-1331-2604), Lucie Leroy ${ }^{1}$, Clément Madec ${ }^{1}$, Louane Matos ${ }^{1}$, Cynthia Tedore1,3(https://orcid.org/0000-0002-3731-9037), Marianne Elias ${ }^{2}$ (http://orcid.org/0000-0002-1250-2353), Doris Gomez ${ }^{1,4}$ (https://orcid.org/0000-0002-9144-3426)

Affiliations:

${ }^{1}$ CEFE, CNRS, Univ. Montpellier, EPHE, IRD, Montpellier, France

${ }^{2}$ ISYEB, CNRS, MNHN, Sorbonne Univ., EPHE, Univ. Antilles, 45 rue Buffon CP50, Paris, France

${ }^{3}$ Univ. Hamburg, Faculty of Mathematics, Informatics and Natural Sciences, Institute of Zoology, Hamburg, Germany

${ }^{4}$ INSP, CNRS, Sorbonne Univ., Paris, France

Corresponding author: Mónica Arias, moarias@gmail.com

Acknowledgements: Authors thank Julien Renoult and Charles Perrier for comments on a previous version of this manuscript. This work was funded by Clearwing ANR project (ANR-16-CE02-0012), HFSP project on transparency (RGP0014/2016). With the support of LabEx CeMEB, an ANR "Investissements d'avenir" program (ANR-10-LABX-04-01).

Author contribution section: $M A, D G$ and $M E$ designed the study; $M A, L L, C M, L M$ acquired field data, CT and MA analysed the data, MA, CT, DG and ME contributed to manuscript writing.

Conflict of Interest Statement: The authors have no conflict of interest to declare 


\section{Abstract}

2 Lepidoptera - a group of insects in which wing transparency has arisen multiple

3 times - exhibit much variation in the size and position of transparent wing zones.

4 However, little is known as to how this variability affects detectability. Here, we test

5 how the size and position of transparent elements affect predation of artificial moths

6 by wild birds in the field. Morphs with transparent elements touching wing borders

7 showed a reduced predation risk, with the effect being the same regardless of the

8 number of wing borders being touched. By contrast, transparent element size had

9 little to no effect on predation risk. Overall, this experiment shows for the first time

10 that transparency offers higher protection when it disrupts prey contour in terrestrial

11 habitats.

12 Keywords

13 background matching, disruptive coloration, transparency, wild bird predators, 14 artificial prey

15 


\section{Introduction}

Predator evasion has promoted some of the most striking adaptations in the living world, including lures, mimicry and camouflage in prey (Ruxton et al., 2004). High transparency (with minimal reflection and absorption at any angle or wavelength) constitutes, by definition, the most effective mechanism of background matching against all types of backgrounds. Transparency is more common in pelagic environments, where there is no place to hide, than in terrestrial environments (Johnsen, 2001), because: 1) small differences in refractive index between water and biological tissues limit reflections that would betray the presence of a prey, 2) UV absorbing pigments are not necessary in the depths of oceans because UV radiation is filtered out by water and 3) often tissues on land need to be thick and/or dense to keep an animal's physical structure in place despite gravity, counteracted by buoyant forces in water but not on land. Contrary to aquatic species, in which animals' entire bodies are often transparent, transparency on land has only evolved as "elements" (i.e. parts of the body). It is currently unknown which visual configurations of transparent and opaque elements are more efficient at reducing prey detectability on land.

On land, a handful of terrestrial groups have evolved transparency, a trait largely represented in insect wings. In Lepidoptera, most species display wings covered by opaque scales. However, transparency has evolved independently several times in butterflies and moths (Gomez et al., 2021). According to recent experimental evidence, translucency (low level of transparency with high amount of light diffusion) can smoothen and blur the animal-environment transition, and reduce body outline detectability in glass frogs (Barnett et al., 2020). The presence of welldefined transparent windows, often found in Lepidoptera exhibiting transparency, reduces detectability in both conspicuous (Arias et al., 2019) and cryptic (Arias et al., 2020) butterflies and moths. However, wing transparency can occur in different forms (Figure 1): as small windows (e.g., as in the moths Attacus atlas, or Carriola 
ecnomoda) or as large windows (e.g., as in the sphinx Hemaris fuciformis) delimited by brownish elements or conspicuous wing borders (e.g., as in the Ithomiini tribe). Wing transparency can also be associated with discontinuous borders, touching prey edges (e.g., as in moths of the genus Bertholdia). Whether the size of transparent windows or their disruption of contour have any effect on prey detectability remains to be studied.

This diversity of forms suggests that including transparent elements can reduce detectability by different mechanisms. For example, a transparent window surrounded by an opaque border could reduce detectability by increasing background resemblance. The larger the transparent area, the larger the proportion of the prey's surface area that matches its background ("background matching hypothesis"). On the other hand, transparent elements in contact with the prey outline can hamper detection as a form of disruptive coloration. In disruptively coloured prey, colours that imitate the background are combined with contrasting elements that are located on the prey border, breaking its visual edges and making it difficult to detect ("disruptive coloration hypothesis") (Cuthill et al., 2005; Stevens \& Cuthill, 2006). Broken edges have been shown to work better than background matching (Cuthill et al., 2005), especially when low and intermediate colour contrast elements are included (Stobbe \& Schaefer, 2008). Additionally, transparent elements touching prey edges can make the prey appear to be of smaller size than it actually is, reducing its perceived profitability and its risk of being attacked, as predation rate is directly correlated with prey size (Berger et al., 2006). To understand the relative importance of these different mechanisms in partially transparent terrestrial prey, we need to investigate the effects of the size and position of transparent elements.

Here, we explored the perceptual mechanisms by which transparent wing windows decrease predation, using wild avian predators of artificial moths, naïve to transparent butterflies and moths. Field experiments with artificial prey models are a common way to explore the behaviour of natural predators in response to the visual 
characteristics of prey and thus to infer the perceptual mechanisms of predation avoidance (Cuthill et al., 2005, 2006; Stevens et al., 2013). We carried out field experiments to analyse the effect of different sizes and positions of transparent "windows" on the attack of prey by avian predators. We predicted that larger transparent windows would decrease prey detectability by background matching, and that transparent windows touching prey outlines would make prey more difficult to detect, presumably via disruptive coloration. Hence, large transparent windows touching wing edges should produce the maximal protection against visual predators.

\section{Material and methods}

\section{Field experiments}

We followed an experimental design similar to that described in Arias et al (2020). Briefly, we performed predation experiments in April and May 2019 in two forests in southern France with evergreen and white oaks as predominant tree vegetation: La Rouvière forest $\left(43.65^{\circ} \mathrm{N}, 3.64^{\circ} \mathrm{E}\right)$ and a large natural wooded area of the Montpellier Zoological Park $\left(43.64^{\circ} \mathrm{N}, 3.87^{\circ} \mathrm{E}\right)$, for three 1-week sessions at each place. We monitored artificial prey survival from predation by bird local communities once per day for four consecutive days after placing them on trunks, and removed them afterwards. Common birds at each site included great tits (Parus major), blue tits (Cyanistes caeruleus), Eurasian jays (Garrulus glandarius), common chaffinches (Fringilla coelebs), golden orioles (Oriolus oriolus) and European robins (Erithacus rubecula). Artificial prey (body and wings) were pinned on evergreen oak (Quercus ilex) tree trunks (>10 cm in diameter, with little or no moss cover) every $10 \mathrm{~m}$. To deter ant attacks, we applied Vaseline and double-sided transparent tape between the wings and the trunk. Prey were placed perpendicularly to the ground and mostly on the north-facing side of tree trunks to reduce direct sunlight reflection that could 
facilitate their detection. We monitored prey survival once per day for the following four consecutive days after placing them on trunks, and removed them afterwards.

\section{$\underline{\text { Artificial moths }}$}

Artificial moths consisted of paper wings and an edible body, as described by Arias et al (2020), and similar to other experiments (Cuthill et al., 2005; Stevens \& Cuthill, 2006). Wings consisted of paper right triangles resembling resting generic moths (i.e., not representing any one particular species). Each triangle was $25 \mathrm{~mm}$ high by $36 \mathrm{~mm}$ wide, giving a surface area of $450 \mathrm{~mm}^{2}$. In choosing a printed-colour and paper combination for the wings, we sought paper that would bear low chromatic and achromatic contrasts with the oak trunk for birds regardless of whether they had the UVS or VS visual system. To choose it, we performed reflectance measurements of evergreen oak trunk colouration (120 measurements on 6 trunks) and we also measured reflectance from laminated grey paper of a range of grey levels. For that purpose, we used a deuterium halogen lamp (Avalight DHS) emitting over the 300 $700 \mathrm{~nm}$ range, including UV to which birds are sensitive (Chen \& Goldsmith, 1986), a spectrophotometer (Starline Avaspec-2048 L), an optical probe (including both illumination and measurement fiber optics) with its tip cut at $45^{\circ}$ (FC-UV200-2-1.5 $\mathrm{x}$ 100, Avantes), and a white diffuse reference (spectralon, WS2). We then calculated colour and brightness contrasts between paper and trunk as potentially seen by birds by applying the Vorobyev and Osorio discriminability model (Vorobyev \& Osorio, 1998) using the pavo package of $R$ software (Maia et al., 2013). We calculated discriminability for both UVS vision (blue tit, (Hart et al., 2000)) and VS vision (shearwater, (Hart, 2001)). We used a forest shade light environment (Gomez \& Théry, 2007). Single photoreceptor noise was 0.1 and cone numbers corresponded to 1:1.7:2.5:3 (U/V:S:M:L) (Hart, 2001; Kram et al., 2010; Rahman et al., 2010; Baumhardt et al., 2014; Ensminger \& Fernández-Juricic, 2014). A Weber fraction of 0.2 was used for the brightness response (as the average reported values for known bird species (Lind et al., 2013)). Within the range of printed grey papers, we found 
126

127

128

129

130

131

132

133

134

that colour Grey155 $(\mathrm{R}=\mathrm{G}=\mathrm{B}=155)$, printed on Canson® sketch paper with a HP officejet pro 6230 printer, was chromatically indistinguishable from trunk coloration (chromatic contrast of $0.47 \pm 0.16$ JND for UVS vision and of $0.41 \pm 0.14$ JND for VS vision), and marginally lighter than oak trunks (achromatic contrast of $1.65 \pm 0.69$ JND for UVS vision and of $1.65 \pm 0.68$ JND for VS vision). The brightness mismatch ensured that opaque uniformly coloured prey were detectable enough to be predated upon at high enough rates to be able to test for differences among treatments. Since achromatic vision is involved in object detection while in motion (Schaerer \& Neumeyer, 1996), it was important that the mismatch occurred on brightness (see Figure 1 for pictures of the different morphs against their natural background during the experiment). This design thus enabled us to explore the effect of transparent windows and their spatial configuration on reducing detectability of imperfectly cryptic prey.

We tested five types of artificial grey moth morphs with different wing characteristics (Figure 1): an opaque morph (O), a morph with small transparent windows (SW), a morph with large transparent windows (LW), a morph with large transparent windows touching the bottom edge of the wing $(\mathrm{BE})$, and a morph with large transparent windows touching all three wing edges (B3E). Morphs that included transparent elements were built by cutting two right triangular windows out of the laminated grey triangle. Dimensions for each triangular window were $10 \mathrm{~mm}$ high by $7 \mathrm{~mm}$ wide (transparency occupying $70 \mathrm{~mm}^{2}$; thus $15 \%$ of the original grey surface) for the SW morph, and $18 \mathrm{~mm}$ high by $14 \mathrm{~mm}$ wide for the LW, BE and B3E morphs (transparency occupying $252 \mathrm{~mm}^{2}$; thus $56 \%$ of the original grey surface). To 
149

150

151

simulate transparent wing surfaces, we then added a transparent film (3M for inkjet, chosen for its high transparency even in the UV range; see ESM, Figure S1) underneath the remaining parts. On top of the moth wings, we added an artificial body made from pastry dough (428g flour, $250 \mathrm{~g}$ lard, and $36 \mathrm{~g}$ water, following (Carroll \& Sherratt, 2013)), dyed grey by mixing yellow, red and blue food dyes (spectrum in Figure S1). This malleable mixture allowed us to make small bodies on which we could record marks made by bird beaks and distinguish them from those made by insects. Morphs were randomised in blocks of 25 artificial moths.

\section{Data collection and analysis}

During monitoring, we considered artificial moths as attacked by birds when their body showed V-shaped or U-shaped marks, or when the body was missing without signs of invertebrate attacks (i.e. no body scraps left on the wings or around the moth on the trunk). We removed all remains of artificial moths attacked by birds, and replaced them when attacked by invertebrates or when the entire artificial prey (wings, body, and pin) was missing, as we could not exclude that the prey item fell down or was blown away by the wind. Non-attacked prey items were treated as censored data in the analyses (i.e. prey that survived at least until the end of the experiment). We analysed prey survival, applying mixed effects and hierarchical (with block nested within location) Cox Proportional Hazards models (Cox, 1972) using the coxme package (Therneau, 2020) in R (R Foundation for Statistical Computing, 2014). We tested four models, each of which included different ways of describing morph visual characteristics as explanatory variables: 1) the morph $(\mathrm{O}, \mathrm{SW}, \mathrm{LW}, \mathrm{BE}$, B3E, Model 1), 2) the number of borders touched by transparent windows (continuous variable with 0 in $\mathrm{O}, \mathrm{SW}$, and LW, 1 border in BE, and 3 borders in B3E, Model 2), and 3) the transparent window size (continuous variable describing the relative surface area of the transparent windows altogether ( 0 for $\mathrm{O}, 0.14$ for $\mathrm{SW}$ and 0.57 for LW, BE and B3E), Model 3), and 4) a model including both transparent window size and the number of borders touched by transparent windows (Model 4). 
177 We used the AICc criterion to compare them. We fitted two additional models to two

178 subsets of our data. The first included only morphs that had the same transparent 179 surface area (LW, BE and B3E) in order to evaluate the effect of the number of 180 borders touched while holding transparent window size constant (Model 5). The 181 second included only complete border morphs (O, SW and LW) in order to evaluate 182 the effect of transparent window size while holding the continuity of the border 183 constant (Model 6). Continuous explanatory variables were scaled for all models.

\section{Results}

185 A total of 618 artificial moths were attacked out of the 1733 used in the field experiment $(35.7 \%$ attack rate). The model with border characteristics as the explanatory variable (Model 2) had the lowest AICc value, followed by the model including both border and surface area characteristics (Model 4), followed by the model with only surface area characteristics (Model 3, Table S1). The model using morphs as the explanatory variable was not among the best models according to the AICc criterion (Model 1, Table S1).

Prey with transparent windows touching the borders (morphs BE and B3E) survived slightly better than morphs with unbroken borders (survival: $68 \%$ for morphs touching the borders versus $62 \%$ for morphs with unbroken borders; Model 2: Cox mixed-effects model coefficient $=-0.09 \pm 0.04, z=-2.2, p=0.03$, Table S2 and

196 Figure 2), suggesting that this characteristic rendered morphs less detectable. 197 However, this difference did not hold when restricting the dataset to morphs with 198 large transparent windows (Model 5, Cox mixed-effects model coefficient = $1990.08 \pm 0.05, z=-1.49, p=0.14$ for a restricted dataset with 1039 prey and 355 200 attacks).

In model 3, morphs sporting large transparent windows had a marginally 202 higher survival compared to the other morphs (morphs LW, BE, B3E $(66 \%$ of 203 survival) as compared to the morph SW (63\% of survival) and the morph and C 204 (61.4\% of survival); Model 3: Cox mixed-effects model coefficient $=0.07 \pm 0.04, z=$ 
1.84, $p=0.07$ ). However, the survival of morphs with different transparent surface areas was not significantly different when restricting the dataset to the morphs with unbroken borders (Model 6: Cox mixed-effects model coefficient $=-0.03 \pm 0.05, z=-$ $0.54, p=0.59$, Table S2 for a restricted dataset with 1040 prey and 393 attacks).

\section{Discussion}

The position of transparent elements was the key visual characteristic that

212 affected moth survival in our experiment. However, the role of transparent window 213 size was less clear. Model 2, which included only border characteristics, had the 214 lowest AICc and also the only significant effect out of all of the statistical models. 215 Adding an effect of transparent window size (Model 4) did not improve model fit. 216 Including only an effect of window size (Model 3) yielded a marginally significant 217 effect. This marginally significant effect was likely a spurious effect driven by border 218 characteristics, however, as two of the three morphs with large windows also had 219 broken borders, whereas the morphs with small (SW) and non-existent (O) 220 transparent windows had complete borders. The fact that SW morphs had slightly 221 higher survival than LW morphs (Fig. 2) further supports the conclusion that the marginally significant effect of window size in model 3 was spurious. It is puzzling that subsetting the dataset to include only morphs with the same transparent window 224 size (LW, BE, B3E) yielded no significant effect of border (Model 5). Our best 225 explanation is that this reduced dataset lacked statistical power due to the lower 226 sample size. However, the lack of significance in this reduced dataset prevents us 227 from completely excluding the possibility that transparent window size had an effect 228 on the results of model 2. Further experiments producing larger datasets are needed 229 to clarify the importance of transparent window size on prey survival. In aquatic organisms, increased camouflage effect for transparency touching

231 animal edges has been suggested, but never tested experimentally. Bagge et al 232 (2016) have found in several hyperiid species (Amphipods, Crustacea) that their 
233 transparent appendages - which facilitate prey detection when visible - have more 234 efficient antireflective nanostructures than the rest of the body, probably due to a 235 stronger selective pressure for camouflage on body contour elements. In terrestrial 236 organisms, Barnett et al (2020) have explored the effect of translucent elements (low 237 transparency and high reflection levels) in glass frogs, which smoothen the animalenvironment transition by increasing environmental reflections around the animal contour. In our experiment, morphs with broken contours had higher survival than 240 morphs with complete contours. We thus provide the first experimental evidence that 241 transparency (high transmission and reduced reflection) can function better when 242 disrupting animal edges. As found in opaque species (Cuthill et al., 2005; Schaefer \& 243 Stobbe, 2006; Fraser et al., 2007), our results suggest that breaking the body outline 244 is more efficient at reducing prey detectability than matching the background while 245 keeping all borders intact. It would be interesting to test whether the advantage of 246 transparent windows disrupting wing edges would remain if the opaque portions of 247 the wings more closely matched bark brightness or had patterns mimicking the 248 heterogeneous visual texture of real tree bark.

Despite the fact that several Lepidoptera species show transparent elements breaking prey edges, including the cossid Zeuzera pyrina, the noctuid Gaujonia arbosi and the erebids Hypercompe robusta, Perina nuda and Senecauxia coraliae, the disruption of wing outline is actually rather uncommon in butterflies and moths 253 exhibiting transparent wing elements. Transparency in wings is sometimes combined 254 with highly visible wing edges as in several bee/wasp mimics, such as the hawkmoth Hemaris fuciformis as well as in the unpalatable Ithomiini tribe. Transparent elements in these latter species may reduce prey detectability as they are large transparent zones that one would expect to enhance background matching (Arias et al., 2019; Mcclure et al., 2019). However, transparency in these species could also

259 potentially function as a means of visual communication such as mimicry (Pinna et 260 al., 2021). It is also possible that in the relatively large-winged Lepidoptera, evolving 
transparent areas touching wing edges is constrained by factors linked to wing

262 strength or flight dynamics. Whether transparent zones not surrounded by opaque borders are indeed more fragile or more sensitive to wind and/or water than opaque patches remains an open question.

However, in contrast to the recent findings reported by Arias et al (2020), we did not find that the mere presence of transparent elements decreases detectability in imperfectly uniformly coloured cryptic prey (no significant survival difference between morphs "O", "SW" and "LW" in Model 3 and Figure 2). Perhaps the overall attack rate in our field experiment was too high to see differences in predation rates among morphs. The attack rate in this experiment was over double that of the study by Arias et al (2020) study carried out under similar conditions $(35.1 \%$ in the current study vs. $14.08 \%$ in (Arias et al., 2020)). Under strong predation pressure, once the most detectable prey morphs in a given area have already been attacked, less

274 detectable prey are more likely to be attacked. This could potentially have led to a 275 homogenization of attack rates among morphs. Another difference between our 276 study and that of Arias et al. (2020) was the number of morphs simultaneously 277 available to predators. Instead of three prey types, including two moth-like types as in 278 Arias et al. (2020), the present study included five moth-like forms with fewer phenotypic differences among them, which may have elicited less divergent predator 280 reactions to each of them. Certain levels of phenotypic similarity, such as that 281 exhibited by imperfect mimics, is often enough to trigger predator generalization and 282 a similar response to distinct phenotypes (Ruxton et al., 2008; Kikuchi \& Pfennig, 283 2010; Arias et al., 2016). Additionally, feeding on many instead of a small number of 284 prey types affects detection of changes in predator foraging behavior. For instance, 285 theoretical approaches suggest that prey switching (i.e. when a given prey becomes 286 relatively more abundant in predators' diet (Murdoch, 1969)) is less marked and 287 more difficult to detect when predators feed on a greater diversity of prey items (van 288 Leeuwen et al., 2013). 
289 Overall, according to the results of our fieldwork experiment, having transparent 290 elements breaking at least one prey border seems to be the most effective mechanism for reducing detectability of prey and subsequent predation.

\section{Data Availability Statement}

293 Field experiment data is available in Dryad (doi:10.5061/dryad.3n5tb2rjb)

294

295

296

297

298

299

300

301

302

303

304

305

306

307

308

309

310

\section{References}

Arias, M., Elias, M., Andraud, C., Berthier, S. \& Gomez, D. 2020. Transparency improves concealment in cryptically coloured moths. Journal of Evolutionary Biology 33: 247-252. Wiley Online Library.

Arias, M., le Poul, Y., Chouteau, M., Boisseau, R., Rosser, N., Théry, M., et al. 2016. Crossing fitness valleys: empirical estimation of a fitness landscape associated with polymorphic mimicry. Proc. R. Soc. B 283: 20160391.

Arias, M., Mappes, J., Desbois, C., Gordon, S., McClure, M., Elias, M., et al. 2019. Transparency reduces predator detection in mimetic clearwing butterflies. Functional Ecology 33: 1110-1119. Wiley Online Library.

Bagge, L.E., Osborn, K.J. \& Johnsen, S. 2016. Nanostructures and monolayers of spheres reduce surface reflections in hyperiid amphipods. Current Biology 26: 3071-3076. Elsevier.

Barnett, J.B., Michalis, C., Anderson, H.M., McEwen, B.L., Yeager, J., Pruitt, J.N., et al. 2020. Imperfect transparency and camouflage in glass frogs. Proceedings of the National Academy of Sciences 117: 12885-12890. National Acad Sciences.

Baumhardt, P.E., Moore, B.A., Doppler, M. \& Fernández-Juricic, E. 2014. Do American goldfinches see their world like passive prey foragers? A study on visual fields, retinal topography, and sensitivity of photoreceptors. Brain, Behavior and Evolution 83: 181-198. Karger Publishers.

Berger, D., Walters, R. \& Gotthard, K. 2006. What keeps insects small?-Size dependent predation on two species of butterfly larvae. Evolutionary Ecology 20: 575 . Springer.

Carroll, J. \& Sherratt, T. 2013. A direct comparison of the effectiveness of two anti-predator strategies under field conditions. Journal of Zoology 291: 279285.

Chen, D.-M. \& Goldsmith, T.H. 1986. Four spectral classes of cone in the retinas of birds. Journal of Comparative Physiology A 159: 473-479.

Cox, D.R. 1972. Models and life-tables regression. JR Stat. Soc. Ser. B 34: 187-220. 
Cuthill, I.C., Stevens, M., Sheppard, J., Maddocks, T., Párraga, C.A. \& Troscianko, T.S. 2005. Disruptive coloration and background pattern matching. Nature 434: 72.

Cuthill, I.C., Stevens, M., Windsor, A.M. \& Walker, H.J. 2006. The effects of pattern symmetry on detection of disruptive and background-matching coloration. Behavioral Ecology 17: 828-832. Oxford University Press.

Ensminger, A.L. \& Fernández-Juricic, E. 2014. Individual variation in cone photoreceptor density in house sparrows: implications for between-individual differences in visual resolution and chromatic contrast. Plos One 9: e111854. Public Library of Science.

Fraser, S., Callahan, A., Klassen, D. \& Sherratt, T.N. 2007. Empirical tests of the role of disruptive coloration in reducing detectability. Proceedings of the Royal Society of London B: Biological Sciences 274: 1325-1331.

Gomez, D., Pinna, C., Pairraire, J., Arias, M., Barbut, J., Pomerantz, A., et al. 2021. Wing transparency in butterflies and moths: structural diversity, optical properties, and ecological relevance. Ecological Monographs e01475. Wiley Online Library.

Gomez, D. \& Théry, M. 2007. Simultaneous crypsis and conspicuousness in color patterns: comparative analysis of a neotropical rainforest bird community. the american naturalist 169: S42-S61.

Hart, N., Partridge, J., Cuthill, I. \& Bennett, A.T. 2000. Visual pigments, oil droplets, ocular media and cone photoreceptor distribution in two species of passerine bird: the blue tit (Parus caeruleus L.) and the blackbird (Turdus merula L.). Journal of Comparative Physiology A 186: 375-387.

Hart, N.S. 2001. Variations in cone photoreceptor abundance and the visual ecology of birds. Journal of comparative physiology. A, Sensory, neural, and behavioral physiology 187: 685-697.

Johnsen, S. 2001. Hidden in Plain Sight: The Ecology and Physiology of Organismal Transparency. The Biological Bulletin 201: 301-318.

Kikuchi, D.W. \& Pfennig, D.W. 2010. Predator cognition permits imperfect coral snake mimicry. The American Naturalist 176: 830-834.

Kram, Y.A., Mantey, S. \& Corbo, J.C. 2010. Avian cone photoreceptors tile the retina as five independent, self-organizing mosaics. PloS one 5: e8992. Public Library of Science.

Lind, O., Karlsson, S. \& Kelber, A. 2013. Brightness discrimination in budgerigars (Melopsittacus undulatus). PLoS One 8: e54650.

Maia, R., Eliason, C.M., Bitton, P., Doucet, S.M. \& Shawkey, M.D. 2013. pavo: an R package for the analysis, visualization and organization of spectral data. Methods in Ecology and Evolution 4: 906-913.

Mcclure, M., Clerc, C., Desbois, C., Meichanetzoglou, A., Cau, M., Bastin-Héline, L., et al. 2019. Why has transparency evolved in aposematic butterflies? Insights 
from the largest radiation of aposematic butterflies, the Ithomiini. Proceedings of the Royal Society B 286: 20182769. The Royal Society.

Murdoch, W.W. 1969. Switching in general predators: experiments on predator specificity and stability of prey populations. Ecological monographs 39: 335354. Wiley Online Library.

Pinna, C., Vilbert, M., Borenztajn, S., de Marcillac, W.D., Piron-Prunier, F., Pomerantz, A., et al. 2021. Mimicry drives convergence in structural and light transmission features of transparent wings in Lepidoptera. bioRxiv 2020.06.30.180612.

R Foundation for Statistical Computing, R.C. 2014. R: A language and environment for statistical computing. Vienna, Austria.

Rahman, M.L., Yoshida, K., Maeda, I., Tanaka, H. \& Sugita, S. 2010. Distribution of retinal cone photoreceptor oil droplets, and identification of associated carotenoids in crow (Corvus macrorhynchos). Zoological science 27: 514521. BioOne.

Ruxton, G.D., Franks, D.W., Balogh, A.C.V. \& Leimar, O. 2008. Evolutionary implications of the form of predator generalization for aposematic signals and mimicry in prey. Evolution 62: 2913-2921.

Ruxton, G.D., Sherratt, T.N. \& Speed, M.P. 2004. Avoiding attack. Oxford University Press.

Schaefer, H.M. \& Stobbe, N. 2006. Disruptive coloration provides camouflage independent of background matching. Proceedings of the Royal Society of London B: Biological Sciences 273: 2427-2432.

Schaerer, S. \& Neumeyer, C. 1996. Motion detection in goldfish investigated with the optomotor response is "color blind." Vision research 36: 4025-4034. Elsevier.

Stevens, M. \& Cuthill, I.C. 2006. Disruptive coloration, crypsis and edge detection in early visual processing. Proc Biol Sci 273: 2141.

Stevens, M., Marshall, K.L., Troscianko, J., Finlay, S., Burnand, D. \& Chadwick, S.L. 2013. Revealed by conspicuousness: distractive markings reduce camouflage. Behavioral Ecology 24: 213-222. Oxford University Press UK.

Stobbe, N. \& Schaefer, H.M. 2008. Enhancement of chromatic contrast increases predation risk for striped butterflies. Proceedings of the Royal Society B: Biological Sciences 275: 1535-1541. The Royal Society London.

Therneau, T.M. 2020. Mixed Effects Cox Models [R package coxme version 2.2-16]. Comprehensive R Archive Network (CRAN).

van Leeuwen, E., Brännström, A., Jansen, V.A., Dieckmann, U. \& Rossberg, A.G. 2013. A generalized functional response for predators that switch between multiple prey species. Journal of theoretical biology 328: 89-98. Elsevier.

Vorobyev, M. \& Osorio, D. 1998. Receptor noise as a determinant of colour thresholds. Proceedings of the Royal Society B-Biological Sciences 265: $351-8$. 
407

408 
409

410

411

412

413

414

415 via projectnoah.org),

c. The erebid Hypercompe scribonia shows windows breaking the bottom edge (wingspan $76 \mathrm{~mm}$, photo: (C) Green Futures). d. the 5 artificial moths used in this study ( $25 \mathrm{~mm}$ high by $36 \mathrm{~mm}$ wide) against a white background and against the natural background used during the experiment.

Figure 2. Survival of artificial prey without transparent elements (O-opaque), with 421 small (SW) and large (LW) transparent elements touching none, one (B1E) or three 422 423 prey edges (B3E). Artificial butterflies were placed on tree trunks and monitored for their 'survival' every day for 4 days. Data from the six weeks during which the experiment was conducted are pooled together. 
a.
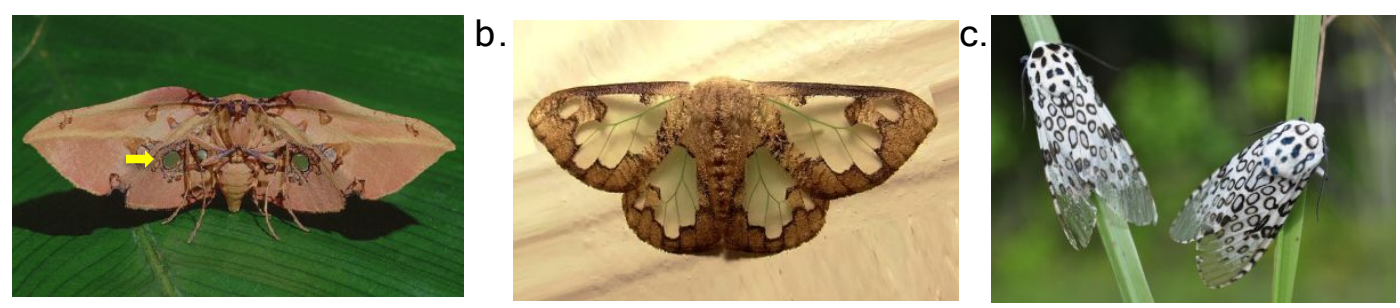

d.
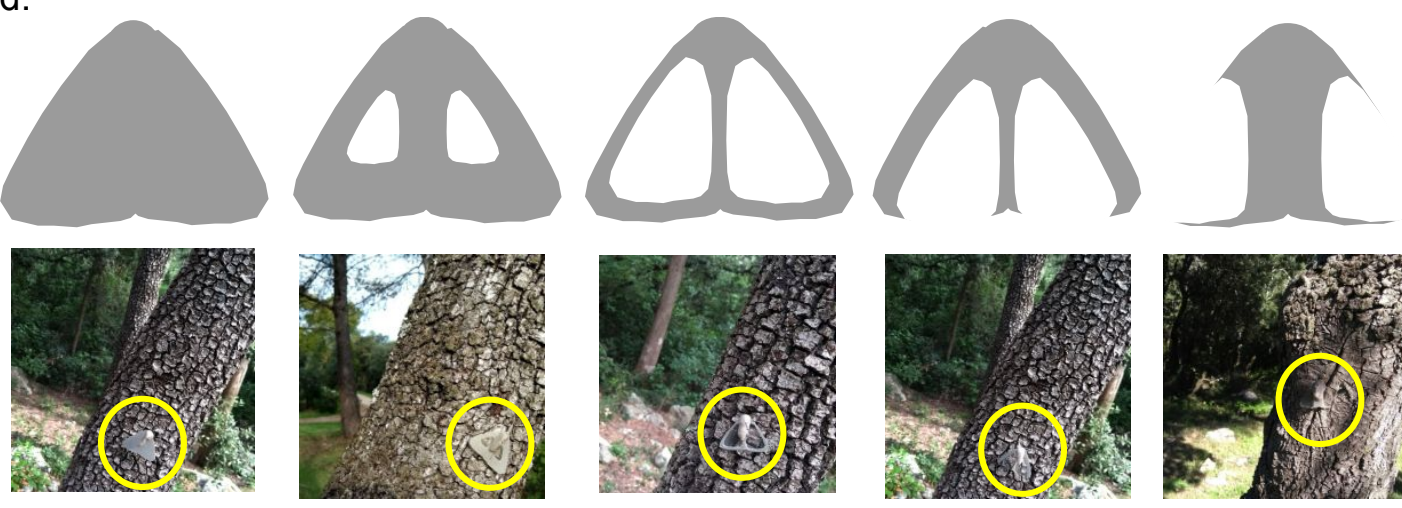

SW
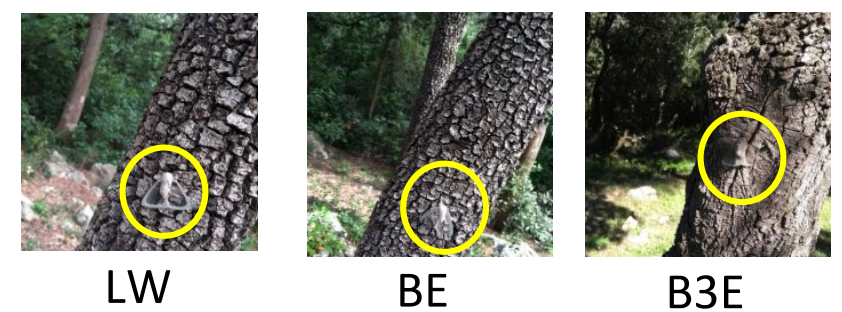

Figure 1 


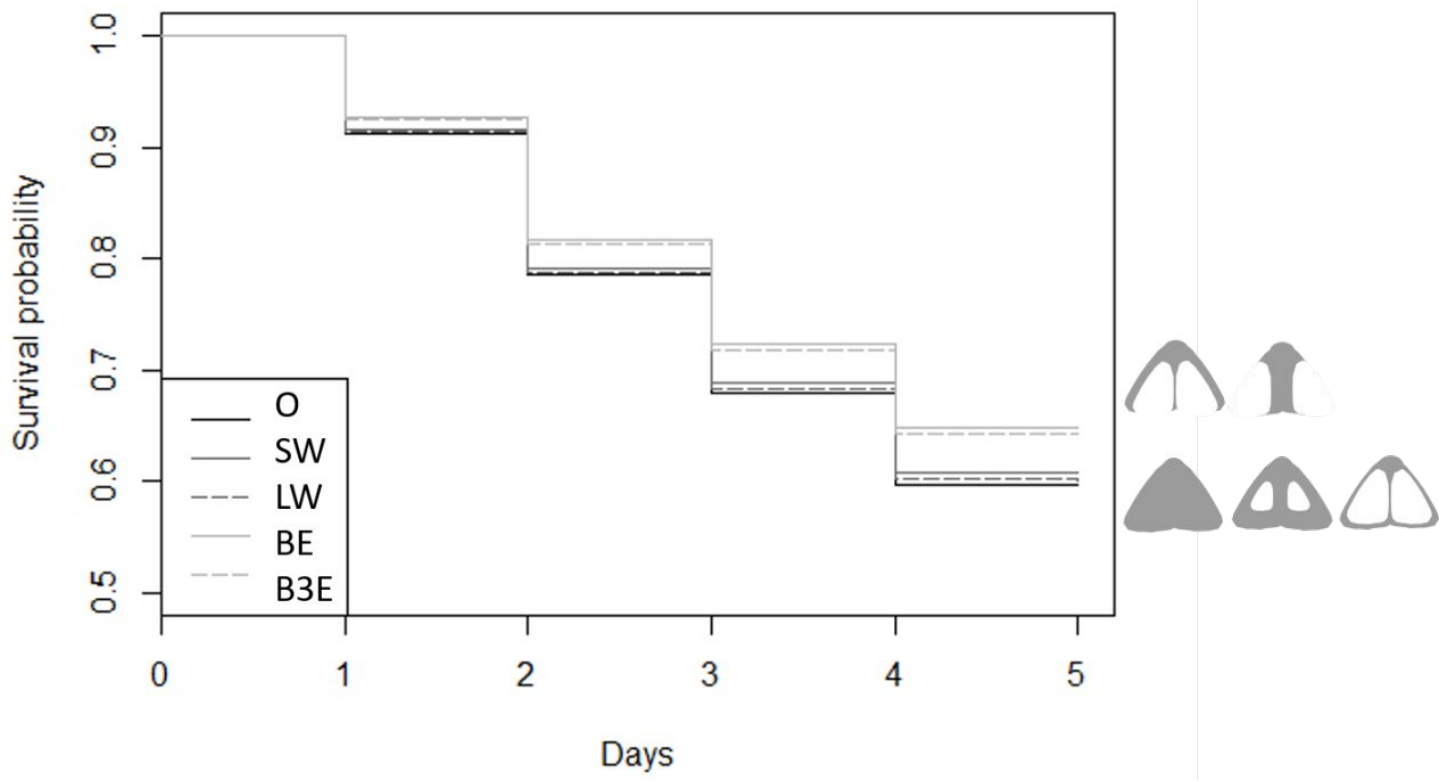

Figure 2 
Electronic supplementary material

Partial wing transparency works better when disrupting wing edges: evidence from a field experiment

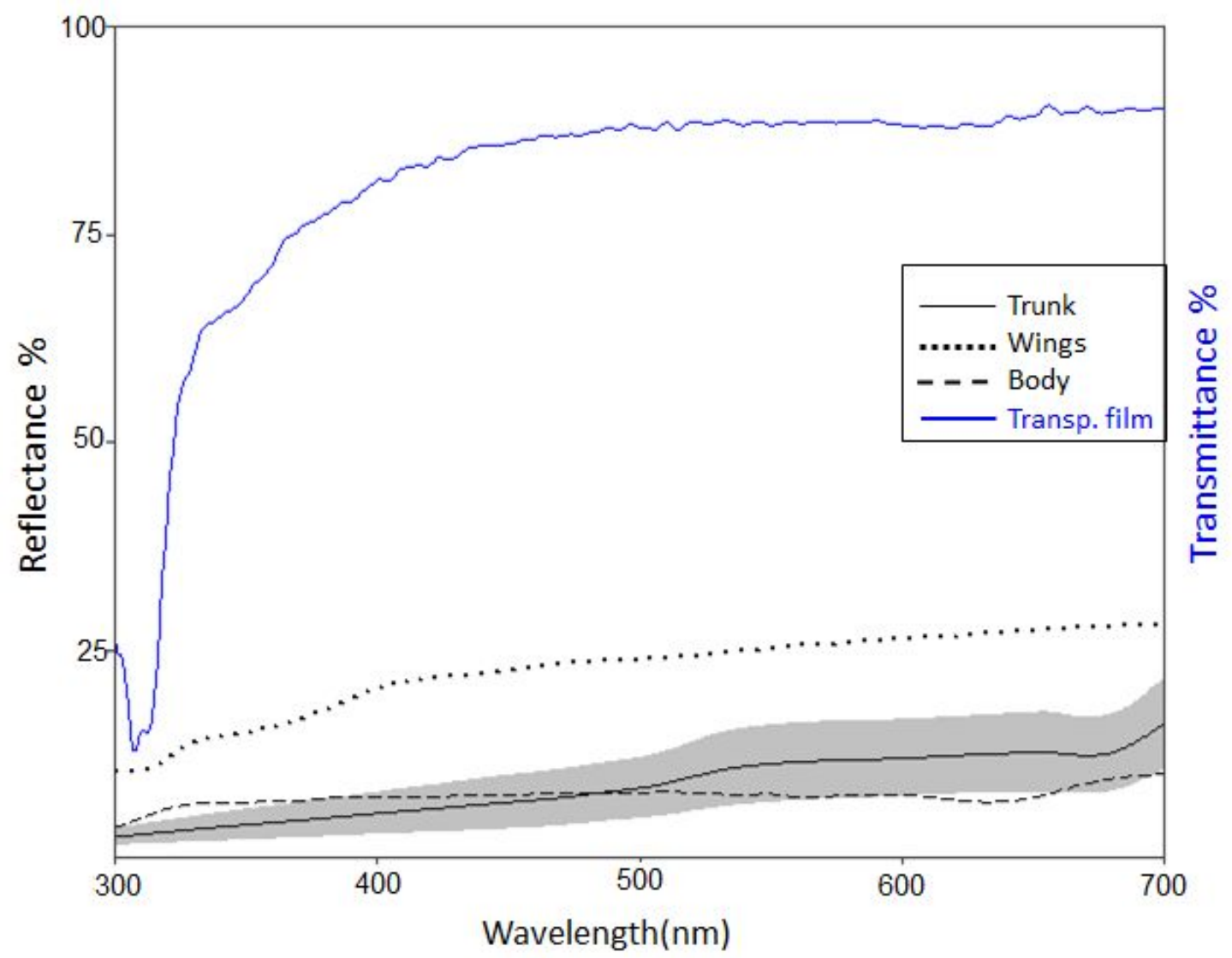

Figure S1. Reflectance spectra of the background (oak tree trunks in solid black line with a confidence interval of \pm 1 standard deviation) and opaque areas: body (dashed line) and opaque wings (dotted line), and transmittance of the transparent film (solid blue line).

Table S1. AICc of of mixed effect and hierarchical (with block nested within location) Cox Proportional Hazards models on morph attack. Models are ranked according to their AICc values, from lowest (best fit) to highest. $K$ stands for the number of parameters and delta AICc for the difference in AICc with the best model.

\begin{tabular}{|c|c|c|c|c|c|c|}
\hline Model & $\begin{array}{c}\text { Number of } \\
\text { prey }\end{array}$ & $\begin{array}{c}\text { Number of } \\
\text { attacks }\end{array}$ & Exp. variables & $\mathrm{K}$ & $\mathrm{AlCc}$ & Delta AICc \\
\hline 2 & 1733 & 618 & Border & 3 & 8571.15 & 0 \\
\hline 4 & 1733 & 618 & Border+Surface & 4 & 8572.66 & 1.50 \\
\hline 3 & 1733 & 618 & Surface & 3 & 8572.85 & 1.69 \\
\hline 1 & 1733 & 618 & Morph & 6 & 8576.59 & 5.44 \\
\hline
\end{tabular}


Table S2. Results from different mixed effect and hierarchical (always with block nested within location) Cox Proportional Hazards model on morph attack

\begin{tabular}{|c|c|c|c|c|c|c|c|}
\hline & $\begin{array}{l}\text { Number } \\
\text { of prey }\end{array}$ & $\begin{array}{l}\text { Number } \\
\text { of attacks }\end{array}$ & Morphs included & Variable & Coef. \pm SE & $z$ & $p$-value \\
\hline Model 2 & 1733 & 618 & All & Border & $-0.09 \pm 0.04$ & -2.2 & 0.03 \\
\hline \multirow{2}{*}{ Model 4} & \multirow{2}{*}{1733} & \multirow{2}{*}{618} & \multirow{2}{*}{ All } & Border & $-0.07 \pm 0.05$ & -1.47 & 0.14 \\
\hline & & & & Surface & $0.03 \pm 0.05$ & 0.71 & 0.48 \\
\hline Model 3 & 1733 & 618 & All & Surface & $0.07 \pm 0.04$ & 1.84 & 0.07 \\
\hline Model 5 & 1039 & 355 & Large windows & Border & $-0.08 \pm 0.05$ & -1.49 & 0.14 \\
\hline Model 6 & 1040 & 393 & Unbroken edges & Surface & $-0.03 \pm 0.05$ & -0.54 & 0.59 \\
\hline
\end{tabular}

Each row shows the explanatory variable used in each model and the results obtained. Models 2-4 were fitted using the entire dataset and are the best models according to the AIC criteria (Table S1). Model 5 explored the survival variation explained by border characteristics between LW ( 0 broken edges), BE ( 1 broken edge) and B3E (3 broken edges) in morphs with a constant transparent surface area. Model 6 explored survival variation explained by transparent surface area between $O$ (0 transparent surface), SW (15\% of the original opaque surface) and LW (56\% of the original opaque surface) thus, only including morphs with unbroken edges. 
